\title{
O Carnaval da turba Futurista
}

\author{
Ana Paula Freitas de Andrade*
}

RESUMO: O artigo trata da repercussão do futurismo italiano no Brasil, a partir da análise de crônicas de Menotti Del Picchia publicadas no Correio Paulistano, entre 1920 e 1922. Nessa época o escritor participou da polêmica sobre a vanguarda italiana veiculada na imprensa paulistana, publicando uma série de crônicas que, ao promover ideias futuristas e criticar a literatura passadista, estabelecem a formulação de um futurismo compósito, adaptado à realidade brasileira; e esboçam as principais teses do movimento modernista.

PALAVRAS-CHAVE: Menotti Del Picchia; Filippo Tommaso Marinetti; Modernismo brasileiro; Futurismo italiano; literatura comparada: Brasil - Itália.

ABSTRACT: L'articolo tratta delle ripercussioni del futurismo in Brasile, partendo dall'analisi di cronache di Menotti Del Picchia, pubblicate sul Correio Paulistano tra il 1920 e il 1922. In quell'epoca lo scrittore partecipò alla polemica sull'avanguardia italiana veicolata dalla stampa paulistana, pubblicando una serie di cronache che, nel promuovere idee futuriste e criticare la letteratura del passato, stabiliscono la formulazione di un futurismo composito, adattato alla realtà brasiliana e tracciano le principali tesi del movimento modernista.

PAROLE-CHIAVE: Menotti Del Picchia; Filippo Tommaso Marinetti; Modernismo brasiliano; Futurismo italiano; letteratura comparata: Brasile - Italia.

ABSTRACT: This article considers the impact of the Italian Futurism in Brazil, based on the analysis of Menotti Del Picchia's chronicles, published between 1920 and 1922, where he promotes Futuristic ideas and criticizes the literature from the

* Universidade de São Paulo, São Paulo (Brasil) - annapaola21@gmail.com

Processo n.2013/20971-0 Fundação de Amparo à Pesquisa do Estado de São Paulo (FAPESP)

DOI: http://dx.doi.org/10.11606/issn.2238-8281.v0i34p31-42 
past, establishing the formulation of a Futurism suitable to the Brazilian reality, and sketching the main propositions of the Modernist movement.

KEYWORDS: Menotti Del Picchia; Filippo Tommaso Marinetti; Brazilian modernism; Italian futurism. 


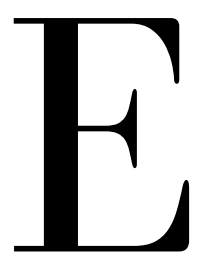

m 1920, Menotti Del Picchia, Oswald e Mário de Andrade, Guilherme de Almeida e Anita Malfatti formaram o grupo dos cinco, que passou a divulgar ideias e palavras de ordem do futurismo italiano, com o objetivo de agitar o cenário artístico brasileiro, rompendo com a ordem estética vigente e escandalizando a academia. Aos poucos, o grupo foi angariando simpatizantes, como Brecheret, Di Cavalcanti, Sérgio Milliet, Cândido da Mota Filho e outros; mas também, conquistando oponentes, sobretudo os parnasianos mais ferrenhos e os críticos literários tradicionais. Os "profetas do novo verbo", ${ }^{1}$ foram rotulados de os futuristas de São Paulo, e, estrategicamente, aceitaram o apelido para atrair a atenção, criar polêmicas e se diferenciarem da ala conservadora.

À época, dentre os cinco, Menotti Del Picchia era o único escritor consagrado, sobretudo por conta do poema narrativo Juca Mulato, publicado em 1917, que caíra nas graças dos leitores e da crítica - em pouco tempo, tinham sido vendidos mais de seis mil exemplares: um fenômeno para o mercado editorial brasileiro da época. Além de escrever para A Gazeta e o Jornal do Comércio, ele acabara de se tornar redator do Correio Paulistano, responsável pela "Crônica Social" e por artigos de primeira página. Entre 1920 e 1922, publicou cerca de mil crônicas,

1 Denominação usada por Menotti, na crônica “Os velhos”, publicada no Correio Paulistano, em 3 de maio de 1921. Nas referências das crônicas de Menotti doravante citadas, $C P$ corresponde a Correio Paulistano. 
que assinou com o próprio nome e os pseudônimos Hélios e Aristófanes. ${ }^{2}$

O escritor bem-sucedido, que passou a denominar-se o arauto do modernismo, soube aproveitar o alcance da grande imprensa para abrir caminho a uma prática literária inovadora no país. E o fez por meio da publicação frequente de crônicas que noticiam os planos da nova geração de artistas, atacam sem dó nem piedade a literatura passadista, difundem e discutem ideias, práticas e obras avanguardistas - para usar o termo italiano importado literalmente pelo cronista.

A essa altura, todos do grupo já conheciam bem o futurismo. Menotti conta que Guilherme de Almeida "lê brochuras futuristas e adora Deus nas alturas e Soffici e Marinetti na terra" $(C P$, 14 out. 1920). Firme no propósito de enterrar definitivamente a "literatice anêmica" (A Gazeta, 18 fev. 1920) que devastava a poesia e a prosa brasileiras, Del Picchia viu na fórmula futurista a "violência irresistível e incendiária"” capaz de derrubar os "velhos e râncidos moldes literários" (CP, 24 jan. 1921). Nas páginas do Correio Paulistano, com a assinatura de Hélios, passou a promover uma ação polêmico-doutrinária, em que o futurismo se estabeleceu como o extrato da discussão e uma espécie de estatuto regulamentador da arte nova.

Com esse objetivo em mente, ele ampliou o caráter de suas crônicas jornalísticas, transformando-as em críticas de arte, reflexões e comentários de cunho sócio-político-cultural, cartas e narrativas breves, além de nelas traduzir trechos de romances e poemas de futuristas italianos. É o que ocorre, por exemplo, em "Correntes estéticas" e "Os futuristas" (CP 23 mai. e 14 out. 1921). Na primeira, o cronista discorre sobre as possibilidades estéticas do futurismo, e traduz os poemas “As rãs" e "As chaminés", de Corrado Govoni. Na segunda, traduz trechos de Mafarka, il futurista, de Marinetti, e tece comentários sobre força a "titânica" desse "revolucionário das letras atuais", fazendo elogios rasgados ao "romance másculo", o qual anuncia o nascimento de "um novo senso de beleza", capaz de arejar "o tempo da arte, iluminando-o com visões libertas e formidáveis".

A vanguarda encerra conteúdos contraditórios, por demonstrar um caráter que é, a um só tempo, avançado e retrógrado. Grosso modo, o primeiro atributo deve-se à identificação com os conceitos formais do industrialismo e do progresso; o segundo, à atitude despótica e bélica

2 A produção jornalística de Menotti Del Picchia do período foi recolhida por Yoshie Sakiyama Barreirinhas, em pesquisa de mestrado sob a orientação da profa. dra. Telê Ancona Lopez (os fac-símiles estão depositados no Setor de Arquivos do IEB-USP).

3 Tradução nossa de fragmento do "Manifesto del Futurismo", de Filippo Tommaso Marinetti, 1909. 
que fundamenta suas concepções teóricas e programáticas, as quais defendem o extermínio de representantes da cultura passadista, e inúmeras "práticas sociais e políticas autoritárias e repressivas" (SUBIRATS, 1993, p. 22). A contradição imanente ao movimento futurista motivou, nos dois primeiros anos da década de 1920, uma enxurrada de crônicas, críticas e notícias sobre a vanguarda italiana, na imprensa literária e na de grande circulação. Tanto a nascente geração modernista, quanto a velha guarda acadêmica sentiram-se obrigadas a tomar partido, em relação às concepções do futurismo e à atuação de Marinetti.

A controvérsia foi a tônica predominante na recepção dos temas futuristas no Brasil, pois não somente os "misoneístas faquirizados" faziam-lhe objeções, mas também os "cantores dos novos Ritmos" tinham lá suas ressalvas. ${ }^{4}$ Mesmo os defensores de uma atitude artístico-ideológica mais incisiva, de cunho marinettiano, passaram por fases de aceitação e rejeição ao futurismo ortodoxo, de modo que seus argumentos sobre preceitos, obras e artistas futuristas compreendiam desde as mais elogiosas e entusiasmadas observações, até as mais depreciativas e adversas.

Na crônica "Futurismo" (CP, 6 dez. 1920), Del Picchia explicita as relações de negação e aceitação que se travaram na discussão sobre o futurismo italiano, e abre o jogo, ao relatar a própria experiência, admitindo que, a princípio, repudiara o futurismo.

Eu que fui um encruado perseguidor desses revoltados, só ao ouvir o nome de Marinetti sentia ânsias de estrangulamento e minhas mãos crispavam-se como tenazes. O leitor, como eu, certamente, prejulgou a nova escola pela sandice dos seus programas iniciais e pelas saraivadas de batatas e assobios que os apóstolos do novo credo recebiam a cada demonstração de força, aparatosamente feitas, nos centros cultos da Europa

Hoje, amansei minhas cóleras. Sem admitir-lhe as loucuras, sem aplaudir-lhe as aberrações, admirei-lhe as belezas. (...) isso não é um bicho de sete cabeças, que nos pintaram os primeiros e bulhentos futuristas. É uma coisa séria, raciocinada, honesta.

Menotti mostra-se criterioso ao acatar determinadas teses, descartar outras e revelar

4 Termos empregados por Del Picchia, para se referir a passadistas e inovadores, respectivamente, em "Na maré das reformas", CP, 24 jan. 1921; e "Novas correntes estéticas", CP, 03 mar. 1920. 
incongruências da nova corrente. Na tentativa, talvez, de apaziguar os ânimos daqueles que ainda resistiam aos novos rumos da arte, enfatiza que o tempo é fator essencial para a assimilação das ideias vanguardistas.

A crônica "Arte nova”, publicada apenas seis meses antes (CP, 22 jun. 1920), atesta esse processo. Nela, o futurismo é classificado de "uma escola enigmática e doida". Menotti, que gosta de ser didático, faz questão de fundamentar a opinião. Segundo ele, a loucura da arte futurista e a ânsia pelo novo são, ironicamente, resultantes de velhas "leis universais que regem o mundo das ideias e das formas", de acordo com as quais "os aparentes ineditismos não são mais que combinações e arranjos de concepções preexistentes e seculares".

Mais uma vez, a fim de apagar os "incêndios erostráticos"5 que volta e meia Hélios atiçava, ao publicar crônicas carregadas num tom futurista mais veemente, o próprio cronista explica que a atuação das "forças filoneístas" é necessária para a evolução da cultura humana, pois "provoca a reação dos elementos conservadores, agitando a estratificação das ideias aceitas".

Tem-se a impressão de que o texto propõe um jogo de contradições, de acordo com o qual, o autor brinca com os conceitos futuristas, instigando o leitor a compor um mosaico dinâmico, em que, pode observá-los de perspectivas diferentes, e refletir sobre eles de modo abrangente. No início da crônica, antes de condenar o futurismo e depois de alinhavar considerações sobre o misoneísmo e o filoneísmo, que "mantêm o equilíbrio social e regulam a marcha evolutiva do progresso", Hélios, numa afirmação muito próxima aos mandamentos do Manifesto do Futurismo, declara que "Os museus são túmulos. A história é um epitáfio". Contudo, termina o texto atacando os futuristas, e defendendo a ideia de que não prestar culto aos gênios consagrados da arte é um sacrilégio. Como sustenta que as coisas devem sempre ser relativizadas, procura justificar a atitude radical dos futuristas, por meio da tese de que eles escarnecem do passado, devido ao decadentismo acentuado do pós-guerra, o qual se traduz numa "loucura crescente de se reformar a face do mundo", que os leva a engendrar "uma arte pueril, absurda e efêmera, que divinizam sob a égide do primitivismo e da ingenuidade", e no amanhã será apenas "uma ridícula memória na história da arte".

Nesse caminho de avanços e recuos, em que opiniões são lançadas, revistas e reformuladas, Menotti vai elaborando um futurismo compósito, adaptado à realidade brasileira, e que esteia

5 Expressão recorrente nas crônicas do Autor, em referência a Erostrato, pastor grego que teria incendiado o templo de Diana em Éfeso - como explica Menotti em "Um pintor argentino (Impressões da exposição Quirós)”, $C P, 17$ nov. 1921. 
as principais teses modernistas, nessa etapa de gestação e difusão do movimento. Hélios encarregou-se da missão de despertar os brasileiros para a realidade do século XX, e, no trabalho de divulgação de informações sobre a vida e a arte modernas, buscava promover a educação dos leitores, preparando-os para a nova arte.

A crônica "Peri" (CP 02 fev. 1921) exemplifica o modo como Menotti combina gesto combativo e espírito professoral. Na representação da guerra contra o passadismo, ele lança um grito de revolta, decretando a morte do índio de José de Alencar, e, ao mesmo tempo, explica por que essa é a única possibilidade de abertura para temas e motivos capazes de representarem artisticamente o mundo do pós-guerra.

Peri está em plena moda. Matam-no, ressuscitam-no, incensam-no, esfolam-no, ele, o pobre guarani lírico, inofensivo e teatral, que fez a alegria das nossas vovós com suas façanhas e a propaganda do Brasil nos mercados europeus.

Mas, o Peri em processo de canonização e em transe de ser assassinado não é em absoluto, a simpática personagem de Alencar. É um símbolo. É o passado. (...) É isso que se quer matar em Peri. E faz-se muito bem.

Em toda a parte do mundo, após a guerra, as coisas mudaram. Mil problemas complexos e imprevistos apresentaram suas incógnitas aos estadistas e pensadores. Na economia, na vida gregária das multidões, na arte, na política surgiram enigmas a solicitar rápida solução. Essas equações trazem termos novos e suas soluções não podem ser procuradas nos velhos elementos de que dispúnhamos como dados conhecidos. (...)

É por isso, e nesse sentido, que se levantou um clamor contra a velharia, contra a ferrugem, contra o bolor, procurando deslocar o problema dos seus falsos eixos para os seus termos justos, focalizando, com audácia, a questão e chamando a atenção de todos para a realidade (...)

Peri fica no seu nicho, no museu literário, entre a veneração póstuma do nosso culto pelo passado, intangido e inerte.

Nessa toada, Hélios vai criando condições à consolidação do movimento modernista no Brasil. Na série de "Cartas a Chrispim", publicadas no Correio Paulistano entre outubro de 1920 e abril de 1921, ele se corresponde com um interlocutor fictício, do interior do Estado, 
que está ávido por "informações e minúcias sobre a vida, obra e figura dos literatos paulistas" $(C P, 4$ out. 1920). A partir do mote, o cronista apresenta aos leitores as ideias e produções dos avanguardistas de São Paulo.

Eles borborilham por aqui, pejados todos, com formidáveis cousas no prelo, na gaveta ou em gestação nos miolos. Esses Júpiters de paletó cintado trazem no crânio Minervas que assombrarão brevemente o Brasil com o fulgor de sua sabedoria. Espere, Chrispim, mais alguns meses...

Quando, em 1921, deu-se a divergência entre os Andrade, Hélios viu o motivo perfeito para simular mais um combate futurista na grande imprensa. O estopim foi o artigo "O meu poeta futurista" (Jornal do Comércio, 27 mai.), no qual Oswald sugere que Mário era adepto da bulhenta escola italiana. Incomodado com o rótulo atribuído aos seus poemas, Mário retrucou com a crônica "Futurista?!" (Jornal do Comércio, 6 jun.), em que faz ressalvas à corrente marinettiana, e coloca questões a serem pensadas sobre o acolhimento do futurismo no projeto estético da arte nova nacional.

O episódio atiçou a crítica tradicional, que aproveitou para lançar farpas na direção de ambos os escritores. Carregando nas tintas, Hélios publica "Odisseia futurista" (CP, 13 jul. 1921), uma espécie de parábola em que pinta a batalha artística que agita a cidade de São Paulo.

Homero, cego vidente, aedo das barbas floridas, empresta-me tua tiorba olímpica, ó criador dos mitos da Hélade, e faz que, em estilo grandíloquo, descreva minha odisseia diária, nesta funambulesca urbe futurista, onde Carlos de Maia, cuja pena lembra a de Alberto Sousa, espanca o admirável Oswald - o maior artista de meu tempo (...)

Transforma, ó troveiro ciclópico, esta crônica chula numa epopeia, onde eu cante a genialidade dos ignorantes de meu tempo, atrelados ao carroção perro do barão de Paranapiacaba, que sacodem as caudas dos artigos maçudos para espancar as ardentes e vívidas abelhas de ouro da lira sarcástica e admirável de Mário Moraes de Andrade! 
No texto em que Hélios pede que ele e seus companheiros sejam reconhecidos como poetas, o campo de combate é o jornal, e o cenário literário paulistano é comparado a Troia em chamas. $\mathrm{Na}$ crônica são combinados planos opostos: o clássico e o moderno. $\mathrm{O}$ primeiro diz respeito à paródia de narrativas épicas, e o segundo, à representação de motivos futuristas. A intertextualidade entre a crônica jornalística e o gênero épico propõe a carnavalização de elementos da tradição narrativa da Antiguidade, como um artifício para atribuir dignidade literária aos conceitos, motivos e práxis futuristas. O cronista da atualidade finca raízes no solo antigo da epopeia, com o objetivo de validar o futurismo e a arte nova, conferindo tratamento literário sério aos argumentos, à linguagem e ao estilo, convencionalmente deslocados da tradição.

Meses depois, em "O momento literário paulista" (CP, 13 dez. 1921), Menotti busca ainda amenizar o impacto causado pelo termo futurista. Ele avalia a adequação de seu uso no contexto artístico de São Paulo, e, em contrapartida, expõe a sua opinião sobre a evolução do movimento italiano.

O que espanta e cria, da parte do público em geral, uma certa prevenção contra a falange nova de estetas em S. Paulo, é sua denominação diabólica de "futurista". O apelido cheira a escândalo. Denominar "futuristas" a Guilherme de Almeida, Oswald d'Andrade, Plínio Salgado, (...) Mário Moraes de Andrade (...) e tantos outros, é usar com impropriedades, um termo que designou na Europa a reação de avanguardistas reacionários, cujos generais eram talentos e cujos aderentes eram imbecis. Esse "futurismo" com proclamações, códigos, disciplina, dogmas, foi um grito de rebelião sincera que depois, desmoralizado, degenerou em blague. Adotado entre nós o termo perdeu (...) a sua significação inicial. Representou apenas o início de um novo movimento estético, sem contudo ter como intenções os princípios dogmáticos da escola de Marinetti, mesmo porque o "futurismo" de S. Paulo odeia tudo quanto é escola. (...)

A fórmula do futurismo paulistano encerra-se, pois, nisto: máxima liberdade dentro da mais espontânea originalidade.

À medida em que se aproximava a data programada para a Semana de Arte Moderna, no Teatro Municipal, Hélios intensificava a propaganda modernista na "Crônica Social". Começou fazendo uma retrospectiva do movimento paulistano. A crônica "Futurismo no Municipal" ( $C P$, 
12 fev. 1922) abre a série, anunciando: "O futurismo nacional, filho legítimo de S. Paulo, vai ter sua consagração em S. Paulo. Pela primeira vez alguém foi profeta em seu país”. O cronista traça um histórico da bandeira futurista, retomando desde a repercussão das primeiras notícias da vanguarda italiana entre nós, a formação e o fortalecimento do grupo reacionário paulistano que abraçou as teses futuristas e adaptou-as à realidade brasileira, até o ajuste de nossa mentalidade artística ao "ritmo universal das novas correntes estéticas".

Hélios defendia com unhas e dentes a ideia de que São Paulo apresentava qualidades e ambientes perfeitos para abrigar a revolução artística que estava prestes a acontecer. No trabalho de divulgação da Semana, fez questão de ressaltar o cosmopolitismo da cidade, e afirmar que a energia construtora e a vitalidade de seus setores social, industrial, financeiro e cultural foram fundamentais para que nela, "antes de qualquer outra unidade de federação", surgisse "um futurismo artístico tão sadio, tão moderno, tão vivo como o mais evolvido de todo o resto do mundo" (CP, 11 fev. 1922).

$\mathrm{Na}$ sua coluna do Correio Paulistano, Menotti fez a cobertura da Semana. Como não poderia deixar de ser, os futuristas italianos e suas teses foram constantemente mencionados nas apresentações. As crônicas "A segunda batalha" e "O combate" $(C P, 15$ e 16 fev. 1922) dão conta do que se passava no Municipal, descrevendo os artistas e a programação, e prometendo coisas do arco-da-velha para todos os gostos. Ele foi o orador da segunda noite do evento, e fez um discurso ${ }^{6}$ em que esclarece questões sobre a escola futurista e Marinetti em relação à proposta modernista.

A nossa estética é de reação. Como tal, é guerreira. O termo futurista, como que erradamente a etiquetaram, aceitamo-lo porque era um cartel de desafio. Na geleira de mármore de Carrara do parnasianismo dominante, a ponta agressiva dessa proa verbal estilhaçava como um aríete. Não somos, nem nunca fomos "futuristas". Eu, pessoalmente, abomino o dogmatismo e a liturgia da escola de Marinetti. Seu chefe é para nós um precursor iluminado, que veneramos como um general da grande batalha da Reforma, que alarga seu "front" em todo o mundo. No Brasil não há, porém, razão lógica e social para o futurismo ortodoxo, porque o prestígio do seu passado não é de molde a tolher a liberdade da sua maneira de ser futura.

6 O discurso de Menotti foi publicado na íntegra pelo Correio Paulistano em 17 de fevereiro de 1922. 
O tumulto que reinou na plateia do Municipal, com assobios, vaias e batatas atiradas aos artistas, em nada diferia das serate futuriste, que havia mais de uma década a vanguarda italiana costumava promover, e, não raro, terminavam com a intervenção dos carabinieri. Ao final, Hélios avaliou o evento, na crônica "A Vitória" (CP, 18 fev. 1922). Como o título sugere, o cronista considerou que os "libertadores da Arte" tinham triunfado, e deixado a "grande ideia" germinando, apesar do mau comportamento da plateia.

Dias depois, foi publicada na "Crônica Social" uma carta que Mário de Andrade enviara a Del Picchia (CP, 23 fev. 1922), comemorando o sucesso da armadilha preparada para os "araras":

Realmente, amigo, outro meio não havia de conseguirmos a celebridade. Era só assim: aproveitando a cólera dos araras. Somos todos os pseudofuturistas, uns casos teratológicos. Somos burríssimos. Idiotas. Ignorantíssimos. Compreendes que com todas estas qualidades só havia um meio de alcançar celebridade: lançar uma arte verdadeiramente incompreensível, fabricar o Carnaval da Semana de Arte Moderna e... deixar que os araras falassem.

Os modernistas podiam, finalmente, festejar o êxito da estratégia posta em prática havia dois anos, quando o grupo dos cinco dera início à renovação da arte nacional, adotando o rótulo futurista, e passando a alardear palavras de ordem e a experimentar preceitos da escola. Numa antecipação do que seria a atitude antropofágica, os artistas de São Paulo devoraram conceitos e práticas do futurismo italiano, a fim de se fortalecerem como grupo, e consubstanciarem a criação de seus ideais. Trabalharam na construção do modernismo, elaborando um método de representação artística orientado pela estética futurista, mas ajustado aos conteúdos e processos sociopolíticos e culturais da realidade brasileira.

\section{Referências}

ANDRADE, M. Futurista?! In Jornal do Comércio, São Paulo: 6 jun. 1921.

ANDRADE, O. O meu poeta futurista. In Jornal do Comércio, São Paulo: 27 mai. 1921.

DEL PICCHIA, M. Livros Novos - "O professor Jeremias". In A Gazeta, São Paulo: (4. 232): 1, 18 fev. 1920.

Os nossos artistas. In Correio Paulistano, São Paulo: (20. 463): 2, 22 jun. 1920.

Cartas a Chrispim I - Eles. In Correio Paulistano, São Paulo: (20. 567): 3, 4 
out. 1920 .

Cartas a Crispim III: Guilherme de Almeida. In Correio Paulistano, São Paulo: (20.577): 3,14 out. 1920 .

Futurismo. In Correio Paulistano, São Paulo: (20. 630): 3, 6 dez. 1920.

Na maré das reformas. In Correio Paulistano, São Paulo: (20. 678): 1, 24 jan. 1921.

Peri. In Correio Paulistano, São Paulo: (20. 687): 2, 02 fev. 1921.

Os velhos. In Correio Paulistano, São Paulo: (20.715): 3, 3 mai. 1921.

Correntes estéticas. In Correio Paulistano, São Paulo: (20. 793): 3, 23 mai. 1921.

Odisseia futurista. In Correio Paulistano, São Paulo: (20. 844): 3, 13 jul. 1921.

Os futuristas. In Correio Paulistano, São Paulo: (20. 933): 5, 14 out. 1921.

Um pintor argentino (Impressões da exposição Quirós). In Correio Paulistano,

São Paulo: (20.967): 5, 17 nov. 1921.

O momento literário paulista. In Correio Paulistano, São Paulo: (20.993): 4, 13

dez. 1921.

Semana de Arte Moderna. In Correio Paulistano, São Paulo: (21. 052): 5, 11

fev. 1922.

Futurismo no Municipal. In Correio Paulistano, São Paulo: (21. 053): 5, 12 fev. 1922.

A segunda batalha. In Correio Paulistano, São Paulo: (21. 056): 6, 15 fev. 1922. O combate. In Correio Paulistano, São Paulo: (21.057): 4, 16 fev. 1922.

A vitória. In Correio Paulistano, São Paulo: (21. 059): 4, 18 fev. 1922.

Uma carta. In Correio Paulistano, São Paulo: (21.064): 4, 23 fev. 1922.

SUBIRATS, E. Vanguarda, mídia, metrópoles. São Paulo: Studio Nobel, 1993.

Recebido em 12/02/2017

Aprovado em 19/05/2017 